\title{
La colección Selgas: Un modelo del coleccionismo finisecular español
}

\author{
Lucía González Menéndez y Ana María Fernández García
}

En un recorrido histórico por el coleccionismo español decimonónico, que en algunos aspectos aún se encuentra por hacer, la colección artística de la Fundación Selgas-Fagalde, radicada en el palacete de El Pito, en la villa costera asturiana de Cudillero, supone un caso excepcional por su singular emplazamiento, por las características del conjunto y por la filosofía coleccionista de sus propietarios. En su creación obraron como imperativos la formación arqueologista e histórica de Fortunato de Selgas y la situación privilegiada como banquero e inversor de su hermano Ezequiel.

Los hermanos Selgas y Albuerne -Ezequiel, Fortunato y Franciscahabían nacido en el seno de una familia acomodada de Cudillero, propietaria de varios negocios comerciales en la villa. Aquel germen de prosperidad familiar se incrementó mediante la dedicación bursátil de Ezequiel, quien, trasladado a Madrid, participó en la creación de importantes empresas bancarias y de otra índole, lo que favoreció la conversión del inicial capital familiar en una fortuna comparable en cuantía a la de otros magnates del momento, como el Marqués de Salamanca o el de Urquijo. Su hermano Fortunato de Selgas, nacido en 1839, dedicó su vida profesional hacia facetas más intelectuales, relacionadas con las Bellas Artes y con la arqueología. Después de terminar sus estudios de Derecho en la Universidad de Oviedo, se orientó hacia una vocación histórico-artística incrementada por sus frecuentes viajes por España y el extranjero.

Ambos hermanos formaron un tándem perfecto: uno con dedicación expresa en los negocios y otro volcado hacia los estudios artísticos, los proyectos arquitectónicos y la restauración monumental. Ambos concibieron la reforma de la primitiva casa solariega de El Pito, ampliando el espacio inicial mediante permutas y nuevas adquisiciones de los terrenos colindantes e ideando un conjunto arquitectónico y artístico sin precedentes 


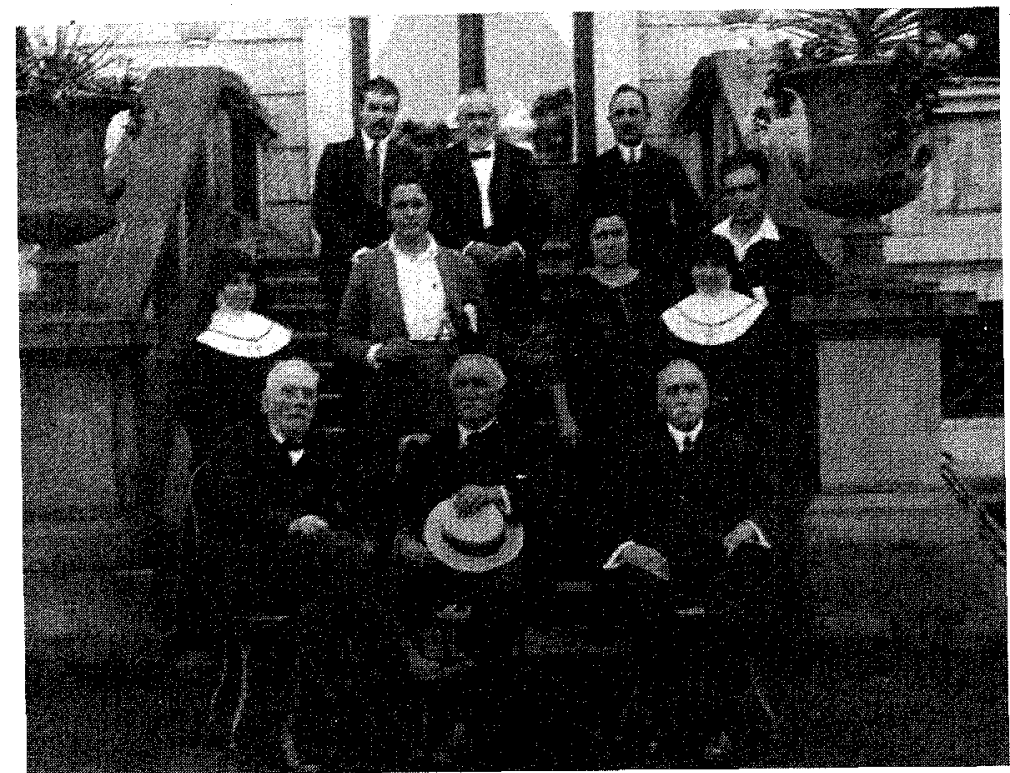

Fig. 1. Sentado en primer plano Ezequiel y Fortunato de Selgas con el rector de la Universidad de Oviedo, Fermín Canela.

en la región asturiana, que en estos años finiseculares acogía la masiva edificación de palacetes de «indianos" que, sin embargo, poco o nada tienen que ver con la filosofía coleccionista de los Selgas ${ }^{~}$.

\section{FORTUNATO DE SELGAS: HISTORIADOR, ARQUEOLLOGO Y REGENERACIONISTA}

A pesar de su formación inicial de índole jurídica, Fortunato de Selgas pronto desarrolló una importante labor en el campo de la arqueología y de la historia del arte. En el año 1880 inició su labor como articulista publicando en revistas como Asturias Ilustrada y Científico-Literaria, Revista de Asturias, en España, o el Boletín de la Sociedad Española de

1 Puede afirmarse que no existió un auténtico coleccionismo de indianos en Asturias. Únicamente algunos acogieron en sus residencias -especialmente en el caso de la colonia de Somao- ciertas pinturas, primordialmente retratos, escogidas más por un afán decorativo que con una voluntad coleccionista. Morales SARO, M. C.: Arquitectura de Indianos en Asturias, Oviedo, 1987; Bermejo LoRenzo, C.: "Concha Heres: Historia de una mujer en América", Arte, cultura y sociedad en la emigración a América, Asturias, 1992. 
Excursiones, trabajos cuyo contenido demuestra su interés y conocimiento de la historia de la arquitectura y los estilos antiguos. El arte prerrománico asturiano, las iglesias valencianas del siglo xIII o la visión de Jovellanos como crítico de Bellas Artes fueron algunos de sus trabajos más señeros en este campo, que motivaron su nombramiento como miembro de la Real Academia de la Historia en 1885 y correspondiente de San Fernando en 1906 ?

Sin lugar a dudas, su principal aportación a la historia del arte y a la arqueología fue la restauración de San Julián de los Prados, realizada entre 1912 y 1915 y pagada con su propio pecunio. En la memoria de la intervención de tan importante edificio alfonsí expone cuál debe ser el criterio de toda restauración programada para un edificio histórico: «se debe evitar el conservadurismo a ultranza, y consiguientemente antirrestaurador, y la restauración radical» ${ }^{3}$. Es decir, las teorías restauradoras o de intervención arquitectónica en el monumento se basaban en un rechazo frontal de las ideas de Viollet-le-Duc (que suponían la eliminación de añadidos posteriores en el edificio para devolverle su pureza original), o las premisas románticas inglesas de la no intervención en el devenir material de las construcciones. Propone, en cambio, Fortunato de Selgas un término medio en el que se respeten los cambios históricos producidos en la materia del edificio y en el que se estudien en profundidad los procesos de una forma documentada y crítica. En San Julián de los Prados Fortunato de Selgas propuso la eliminación de los añadidos postizos barrocos, como las cubiertas abovedadas, para recuperar la primitiva disposición del artesonado de madera, suprimió las rejas de las ventanas y los encalados, además de devolverle al pórtico de acceso su diseño original.

Así, en una de sus principales actividades, la de arqueólogo-restaurador, se convirtió en el prototipo de erudito, de perfecto conocedor de la historia y en un innovador en las prácticas habituales de la disciplina en España, hasta entonces dirigidas por las premisas rigoristas de Viollet-le-Duc. Su

\footnotetext{
Datos biográficos extraídos de Manzanares Rodríguez MIR, J.: «Don Fortunato de Selgas y Albuerne y su restauración de Santullano de los Prados", prólogo de la edición facsímil de la obra de Fortunato de Selgas, La Basílica de San Julián de los Prados (Santullano) en Oviedo, Oviedo, 1990, pág. XIII.

3 Tal teoría restauradora se ajustaba perfectamente con las ideas del que fuera su gran amigo Vicente Lampérez Romea, quien en el año 1913 pronunció en Madrid una conferencia exponiendo exhaustivamente sus criterios. El texto de la charla, LAMPÉREZ y ROMEA, V.: La restauración de los monumentos arqueológicos (teorias y explicaciones), Madrid, 1913, concuerda con los criterios expuestos por Fortunato de Selgas en su obra La Basílica de San Julián de los Prados en Oviedo (Estudio de las restauraciones efectuadas en 1912-1913), Madrid, 1916.
} 
contacto personal con Vicente Lampérez y Romea (1861-1932) cuajó en una estrecha colaboración entre ambos, de forma tal que el ilustre arquitecto no tuvo nunca inconveniente en firmar los proyectos del asturiano. Ambos profesaron idénticas directrices acerca de la intervención monumental, uno desde el punto de vista arquitectónico y el otro como un aficionado a las bellas artes y a la arqueología, que fundamentaba su discurso histórico del edificio en un extenso acopio de datos, y que prescindía absolutamente de la excavación de los sustratos terrestres. La actitud de Fortunato de Selgas se corresponde con la del ilustrado decimonónico, interesado por varios aspectos de la cultura nacional o regional que actúa a la vez como historiador del arte, como conservador, y que manifiesta cierto interés arqueologista por el rescate de piezas antiguas. Tal hecho está confirmado por la existencia en la propia colección de El Pito del cancel prerrománico procedente de la basílica de Santianes de Pravia, o del Ara Sextiana de Carrió.

Este interés de Fortunato de Selgas por la historia y el arte regionales conecta con los premisas regeneracionistas de su círculo intelectual asturiano, el «Grupo de Oviedo» o «Generación de la Quintana», compuesto por un grupo de catedráticos y profesores de la Universidad de Oviedo, inspiradores de la Extensión Universitaria entre los que destacan las figuras de don Félix Aramburu o el propio Fermín Canella. Todos ellos estaban vinculados al krausismo hispánico, emanado de la Institución Libre de Enseñanza y del propio Giner de los Ríos, entendido como un movimiento librepensador en el que la formación del individuo se convierte en la idea central. Así, la educación conduciría a un renacimiento ético, asiento en última instancia de la libertad y del progreso de la humanidad. Fortunato de Selgas comulgó por completo con las teorías institucionales comunes a su círculo de amistades en la Universidad de Oviedo. Aquel grupo erudito, preocupado por la regeneración moral y cultural de la sociedad asturiana, encontró en él uno de sus baluartes en lo referente a la realización material de sus proyectos. Como ellos intentó completar el conocimiento del pasado de la región, interesándose por los estudios locales y en el plano pedagógico creó y dotó una institución docente, las Escuelas Selgas, como centro modelo de las nuevas premisas educativas promovidas por el krausismo hispánico ${ }^{4}$.

Falleció Fortunato de Selgas el 7 de noviembre de 1921 en Madrid, siendo su cadáver conducido a la iglesia de El Pito, para ser enterrado

TerRón Bañuelos, A., Y Mato Díaz, A.: Un modelo escolar integrador y reformista: La fundación Escuelas Selgas, Oviedo, 1992. 
en la cripta-panteón por él diseñada. De su personalidad escribiera su gran amigo y compañero Fermín Canella: «Hombre de tales saber, gustos y medios, supo hacer de su casa de Madrid y de su residencia de El Pito moradas, no a la manera de fastuosa residencia de una persona adinerada, sino de selecta mansión de un inteligente y culto amador y protector del Arte ${ }^{5}$.

\section{MORADA Y RELICARIO: EL CONJUNTO ARQUITECTÓNICO DE LOS SELGAS EN CUDILLERO}

Selecta mansión fue sin duda la construida en El Pito por iniciativa de los hermanos Selgas. Con las sucesivas construcciones y ampliaciones se modificó por entero el primigenio solar de la familia, ampliando el espacio mediante compras y permutas de los terrenos colindantes. Haciendo gala de su formación autodidacta como arquitecto Fortunato de Selgas proyectó cada una de las edificaciones que componen el conjunto: el palacete, a modo de una villa francesa, el pabellón de tapices, de claro diseño italianizante y el denominado «Chalet», o casa del servicio, que es una trasposición de las viviendas unifamiliares suizas puestas de moda en las revistas ilustrádas finiseculares. La construcción de la Quinta, edificio señero del conjunto se completó entre los años 1883 y 1895, siguiendo las directrices de sus propietarios que controlaban muy directamente la evolución y transformaciones de la obra. En ella concurrieron reputadas casas comerciales principalmente extranjeras como Kaeller \& Cie, BlatonAubert o Huber Frerès y algunas nacionales como La Imperial.

Para la decoración pictórica de los techos de la Quinta, la familia Selgas recurrió a los pintores asentados durante la etapa estival en la vecina localidad de Muros del Nalón. Esta colonia artística, inspirada por Casto Plasencia, frecuentó desde 1884 los salones de El Pito estableciéndose una sólida relación de amistad, que cuajó en la realización por parte de Plasencia de los techos del edificio y a la inversa con el proyecto de colonia estable diseñado por Fortunato para sus amigos «coloniales» ${ }^{6}$. 1924.

5 Canella, F.: «Los Selgas». Boletín del Centro de Estudios Asturianos, número 2, Oviedo,

6 Casto Plasencia pretendía establecer una colonia estable a orillas del Nalón, en las marismas cedidas al efecto por el Marqués de Muros. Fortunato de Selgas diseñó un complejo integrado por un edificio central con embarcadero al modo de chalet suizo (similar al edificio de El Pito) con viviendas unifamiliares para cada integrante inspiradas en la arquitectura popular asturiana. El proyecto se truncó por los inconvenientes burocráticos en la gestión del expediente y, sobre todo, 


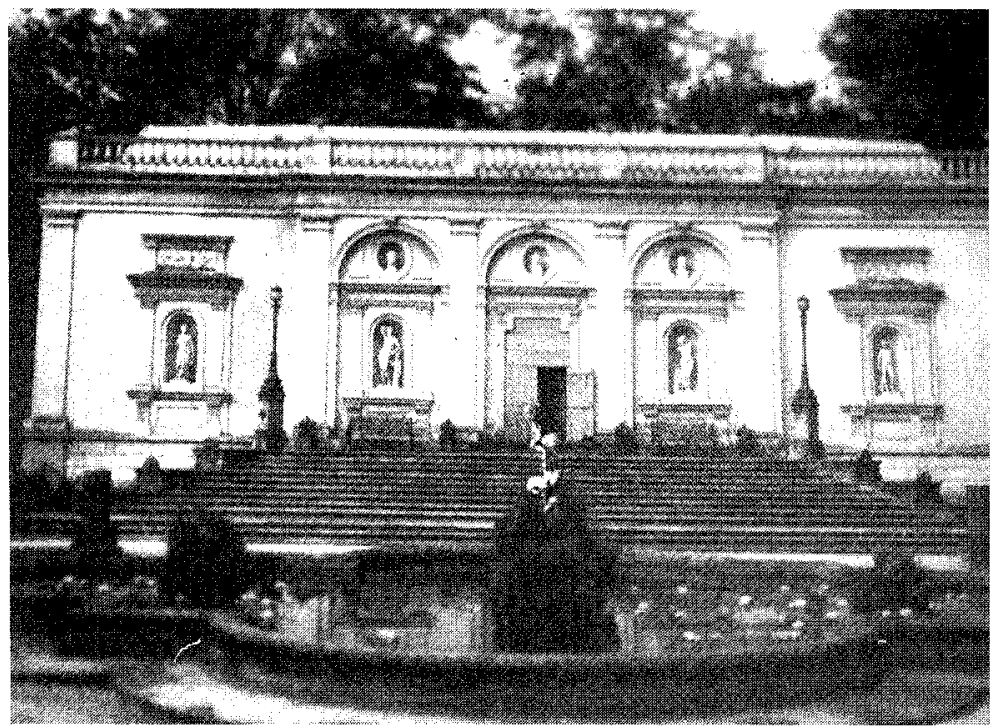

Fig. 2. El Pabellón de Tapices.

Después del fallecimiento del pintor en mayo de $1890^{7}$ continuó los trabajos como artista igualmente relacionado con el grupo de trabajo artístico de Muros, Manuel Domínguez.

El diseño historicista de los edificios, el recurso a determinadas firmas comerciales e incluso la contratación de Plasencia y Domínguez (que habían trabajado en Linares y en otros palacetes de la capital) para los trabajos decorativos atestiguan la vinculación estrecha entre los Selgas y los modos de la alta burguesía madrileña. Se utilizan en El Pito las mismas tipologías arquitectónicas, idéntica composición decorativa e incluso se recurre a un espíritu o filosofía coleccionista que

por la muerte inesperada del pintor. El Carbayón, Oviedo, 24 de septiembre de 1888. Carta de Casto Plasencia a Don Ezequiel de Selgas, 3 de octubre de 1888. Archivo de la Fundación SelgasFagalde.

Precisamente Castro Plasencia estaba trabajando en la obra «La Noche» cuando le sobrevino la muerte. Tal pieza inacabada, que así fue colocada en el palacete de El Pito por sus discípulos Lhardy y García Sampedro, sirvió de dosel al túmulo mortuorio de Plasencia instalado en su estudio del Pasaje de la Alhambra, y reproducido en el dibujo de Joaquín Sorolla publicado en mayo de 1890 en La llustración Española y Americana. 
tiene su relación con las actitudes tópicas propias de esa capa social capitalista.

Los edificios se rodearon con un conjunto de jardines cuidadosamente diseñados, recreando una tipología de tradición en España desde el Renacimiento. Los trabajos de jardinería fueron realizados por el francés Henri Rigoreau Jouvert, formado en Versalles y diseñador de los jardines del palacio de Liria de los duques de Alba. En el entorno natural de El Pito nos encontramos ante una doble influencia y la concepción de la naturaleza dominada oscila así entre la idea casi selvática, y por supuesto romántica, del jardín inglés y el espíritu regulador de la jardinería francesa ${ }^{8}$. Todas las esquinas, los setos y los espacios verdes están realzados con estatuaria clasicista y restos arqueológicos que dotan al parque de un carácter de museo al aire libre que a su vez subraya la concepción de relicarios artísticos de los edificios a los que el jardín envuelve.

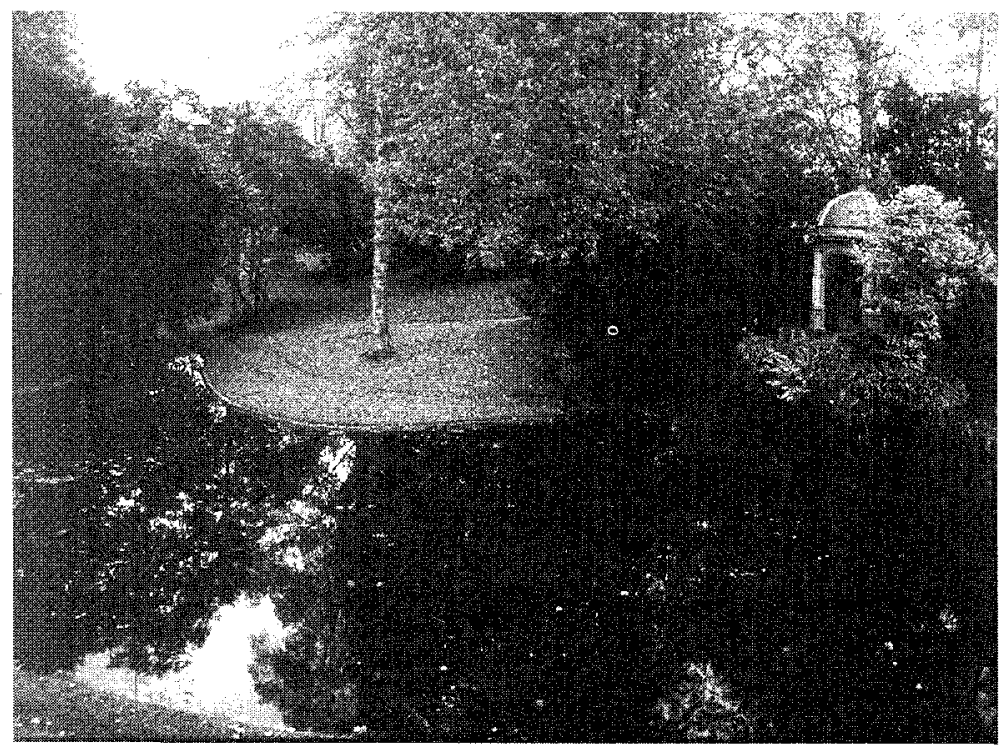

Fig. 3. Vista del Parque inglés que rodea a los edificios.

* Fernández López, A.: «Los jardines del palacio Selgas o la idea de la naturaleza sacra», Liño, número 6, Oviedo, 1986, págs. 59-67. 
Fuera del recinto residencial, los hermanos Selgas y Albuerne llevaron a cabo una serie de construcciones de índole filantrópica: la iglesia del Jesús Nazareno, la rectoral (hoy Cuartel de la Guardia Civil) y las Escuelas Selgas. Esta preocupación por la mejora de las condiciones materiales del pueblo de origen fue norma común en la colectividad indiana en Asturias en un intento revelador de mostrar la preeminencia social conseguida y su interés por el bienestar conciudadano. En tales construcciones se recurre a la ya tradicional recreación de los estilos históricos propia del cambio de siglo, siguiendo por otra parte la norma ecléctica iniciada en los edificios de la Quinta.

La concepción y estilo del conjunto de edificios de El Pito no difiere en esencia de las construcciones erigidas por la alta burguesía o nobleza madrileña del fin de siglo. A las afueras de la villa de Cudillero no existían los problemas de limitación parcelaria de la capital y la libertad para una creación singular e impactante era casi absoluta.

\section{LA COLECCIÓN DE ARTE DE LOS HERMANOS SELGAS}

La dificultad principal para poder perfilar la historia del coleccionismo español finisecular radica en la posterior disgregación de los conjuntos entre los herederos o por la venta legal o clandestina de buena parte de las obras ${ }^{9}$. En el caso de la colección Selgas-Fagalde la voluntad de sus descendientes y de la fundación actual permite estudiar sin ninguna omisión un ejemplo señero de este tipo de actividad que se sumaba al tradicional mecenazgo de la Corona española y de ciertos nobles peninsulares durante los siglos precedentes.

Hay muchos tipos de coleccionistas y las razones que los mueven son muy variadas. Ezequiel y Fortunato de Selgas pertenecen al tipo de coleccionista que reúne objetos de arte como una forma de conocimiento, como una forma de preservar el pasado a la vez que de satisfacción estética ${ }^{10}$. Esta voluntad de recrear el pasado tiene indudablemente mucho que ver con su actividad como arqueólogo e historiador de arte.

\footnotetext{
9 La dificultad para realizar este tipo de trabajos de investigación acerca del coleccionismo español finisecular ha sido expuesta por PÉREz SÁnCHEZ, A.: «La colección Cambó en el coleccionismo de su tiempo", Catálogo de la Colección Cambó, Museo del Prado, Madrid, 1990, págs. 41-42.

10 La definición de este tipo de coleccionista ha sido recogida por Enric Bou en su artículo «El arte del coleccionista (a propósito de Raimón Casellas", en La colección Raimón Casellas, Catálogo de Exposición, Madrid, 1993.
} 
Y de hecho, al aproximarnos a la colección Selgas lo primero que sorprende es su diversidad o heterogeneidad. Cuadros, esculturas, tapices, muebles de época, ornamentos y objetos litúrgicos, bordados eruditos, piezas de porcelana o arqueológicas, en suma, toda suerte de objetos reunidos con un último afán de recreación del pasado que responde también a una actitud muy relacionada con los historicismos de finales del siglo XIX y en cuya órbita se han de encuadrar las actividades de nuestro personaje como historiador, arqueólogo y coleccionista.

Así, durante la segunda mitad del siglo XIX el interés por la adquisición de objetos artísticos con connotaciones históricas es prácticamente consustancial a un determinado nivel de riqueza. Se trataba de decorar la propia residencia de un modo acorde con la moda y con lo que en la sociedad de ese momento era entendido por «culto» $y$ «refinado».

Y esa moda no es otra que la pasión por las antigüedades, que había nacido en Inglaterra por el interés que suscitaron los hallazgos arqueológicos de Pompeya y Herculano y desde entonces no dejará de crecer y ampliar sus fronteras cronológicas y temáticas ${ }^{11}$. Es precisamente en este momento de finales de siglo en que las ciudades están cambiando drásticamente su fisonomía hacia la modernidad, cuando entre las élites económicas y cultas de la sociedad triunfan los historicismos artísticos, todo aquello que rememora modos de vida ya obsoletos y quizá por ello llenos de un atractivo irresistible. Se comienza por la adquisición de piezas sueltas de sabor renacentista, barroco o rococó con la intención de decorar los salones de un modo acorde a la moda imperante y - si existe una fuerte afición y los medios económicos lo permiten- se termina por formar una auténtica colección como la que nos ocupa.

Este es a grandes rasgos el proceso seguido por la colección Selgas. No existió un ánimo claro y definido de crear una colección «a priori», como el que estamos acostumbrados a ver los coleccionistas actuales. Lo que guía a Exequiel y Fortunato de Selgas a adquirir obras de arte y en general toda suerte de objetos valiosos o simplemente curiosos es su gusto por los mismos, además de su interés por el arte y la historia. De ello nos dan fe los comentarios al respecto dejados en diarios y cartas familiares, en los que se alude a compras realizadas tanto en España como en los países europeos que frecuentemente visitaban ${ }^{12}$.

Oddy, A.: The Art of the Conservator, British Museum Press, London, 1992.

12. Tanto los diarios de Don Fortunato de Selgas como las cartas familiares carecen de indicaciones acerca de una supuesta voluntad de formación de una colección de arte. Únicamente se 
Y cuando los hermanos Selgas deciden levantar en su villa natal un palacete de recreo al estilo de las mansiones de la elite financiera madrileña -de los que por otra parte ellos mismos formaban parte-, situadas casi todas en el barrio de Salamanca, es cuando esas compras se intensifican y se establecen relaciones casi "en exclusiva» con determinados anticuarios, proveedores artísticos de esa burguesía a la que hemos aludido. Se trataba, pues, de levantar un palacete al que no le faltase detalle representativo del gusto de una clase social muy concreta, y de esa intención primera se deriva la formación de una colección de arte perfectamente representativa de lo que fueron las colecciones historicistas de finales del siglo XIX.

A partir de 1885, momento en que las obras de La Quinta están muy adelantadas y se aborda el capítulo de su decoración, se intensifican los contactos de los hermanos Selgas con anticuarios y casas de decoración. Por lo que respecta a las segundas, hay que señalar la procedencia francesa de la mayoría de ellas. Así, los pavimentos de marquetería se encargan a la sociedad franco-suiza Kaeffer \& Cia., que se anuncia como "la única y exclusiva fábrica de parquets y mosaicos suizos en París». Las decoraciones de los techos en los que más tarde se insertarán grandes lienzos de tema alegórico son realizadas por la casa Huber Frères \& Cía., también de París, medalla de oro en la exposición de 1878 y especializada en decoraciones en cartón piedra, madera y mármol.

El sello francés no se restringe únicamente a la decoración de las dependencias interiores, sino que abarca también los jardines que rodean los edificios. Ya hemos señalado la autoría francesa del trazado de los mismos, y de la casa francesa de Louis Leroy en Angers proceden la mayor parte de las semillas y especies con que se puebla. Resulta también significativa la procedencia francesa del invernadero que se instala en la parte trasera de los jardines y que constituye un señalado ejemplo de la arquitectura de hierro y cristal de finales de siglo. Fue encargado a la Maison Lefebvre Dormois de París, cuyos operarios se desplazaron expresamente a Cudillero para su instalación y habilitación ${ }^{13}$.

Por lo que respecta a la compra de obras de arte y en general objetos de valor histórico o artístico, las vías de adquisición predominantes son

\footnotetext{
da cuenta del interés por determinadas compras como meras adquisiciones de objetos preciosos o de interés decorativo para la Quinta de El Pito.

is El expediente de adquisición, traslado y permisos de envío se encuentra en el Archivo de la Fundación Selgas-Fagalde de Cudillero.
} 
La colección Selgas: Un modelo del coleccionismo finisecular español

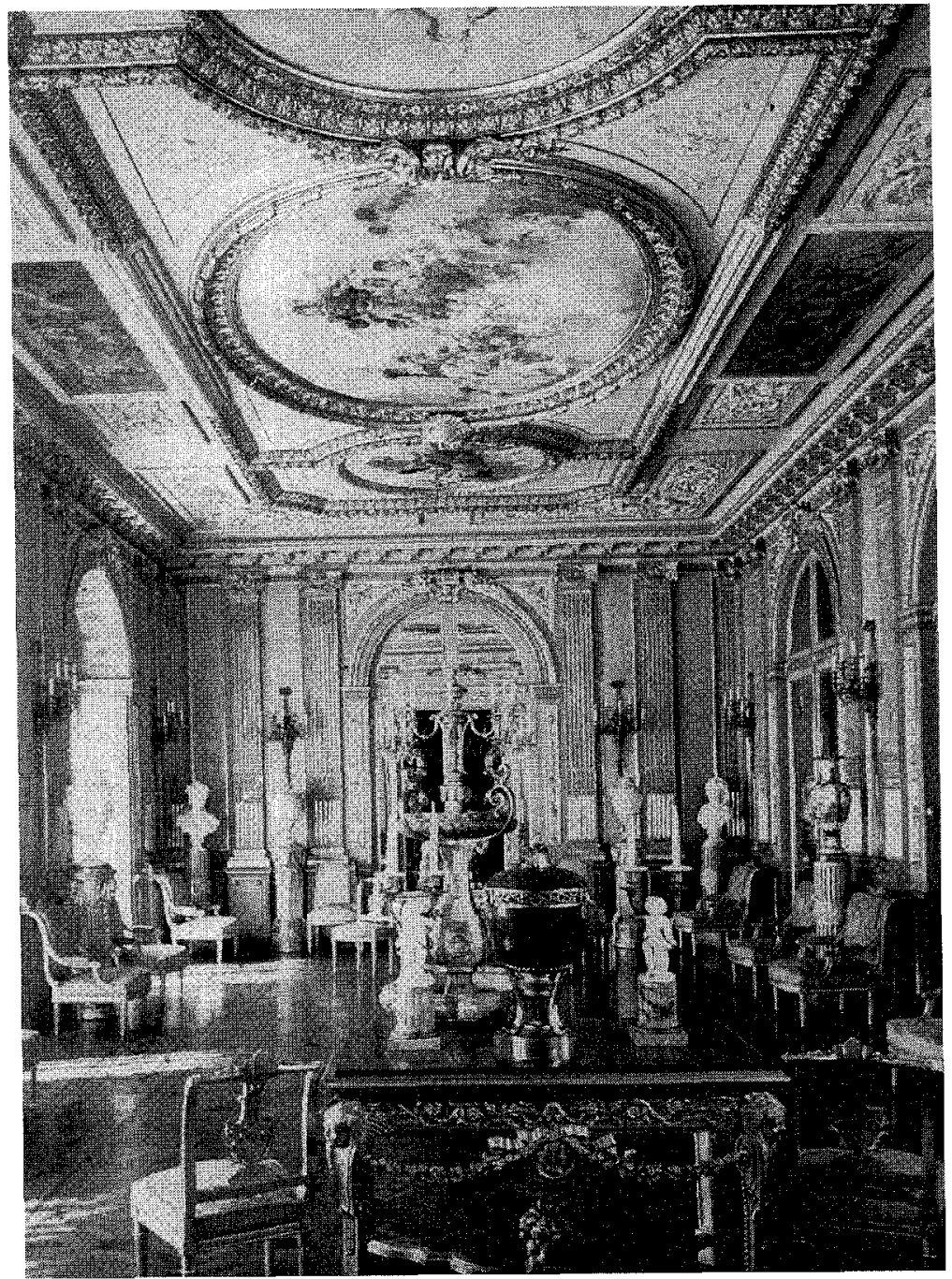

Fig. 4. Salón Luis XVI de la planta principal de La Quinta. 
nacionales. Se tiene noticia de compras en el extranjero, tanto en subastas - a las que Fortunato de Selgas era muy aficionado- como en comercios especializados, pero en los años en que se procede a la decoración del palacete ambos hermanos están en Madrid y es en esta ciudad en donde adquieren la mayoría de las piezas que hoy constituyen el grueso de la colección.

Destacan por el volumen de las compras realizadas dos firmas: la de Rafael García Palencia, que poseía un negocio de antigüedades situado en la calle Fuencarral y la de Pedro Bosch, artífice de la compra de varios de los lienzos más importantes de la colección. Y lo que se desprende del examen de las facturas conservadas en el archivo de la Fundación SelgasFagalde es la homogeneidad en lo que respecta a la procedencia de las piezas. Prácticamente todas ellas fueron adquiridas a anticuarios $y$, por tanto, sometidas a reparaciones y restauraciones que han determinado su estado actual de conservación ${ }^{14}$.

Así, por lo que se refiere a los cuadros, resulta sorprendente la similitud de marcos y bastidores que comparten obras de cronología y procedencia muy dispar. Incluso en numerosos casos se han alterado los formatos originales, recortando o añadiendo telas, con el fin de presentar lotes o conjuntos de cuadros que resolvieran de un modo eficaz las preocupaciones ornamentales del comprador.

Particularmente ilustrativo de este hecho resulta la galería de retratos del Vestíbulo. Están colgadas en esta sala ocho telas de gran formato, todas ellas retratos de personajes del siglo XVII. Y pese a la diversidad de estilos y cualidades los cuadros presentan idénticas medidas, en un artificial intento de homogeneización del conjunto. El lote del Vestíbulo revela además la voluntad de «ennoblecimiento" que esta galería de personajes ilustres delata. A falta de retratos familiares que corroboren el linaje familiar, la burguesía enriquecida de finales de siglo no duda en adquirir su propia galería de retratos que, al igual que lo había venido haciendo la nobleza en sus palacios, sitúa en el umbral de la propia residencia. De estas «debilidades nobiliarias» supieron aprovecharse los anticuarios de

14 Tales anticuarios intervenian directamente en las piezas antes de su traslado a Cudillero: dorado y cambio de marcos, restauración superficial de los lienzos, o incorporación de elementos en las piezas mobiliarias son constantes en las adquisiciones realizadas por los Sesgas en estos establecimientos. Un ejemplo al respecto es la compra de un mueble de concha a la casa madrileña García Palencia previamente restaurado y al que han añadido «garras en vez de bolas, esto hará más bonito». Carta de Beatriz García Palencia a Ezequiel de Selgas, 26 de septiembre de 1889. Archivo Fundación Selgas-Fagalde. 
finales de siglo, y un ejemplo de ello lo tenemos en este Vestíbulo en el que alternan piezas de enorme calidad con copias eclécticas de trazo apresurado.

Pero no se debe considerar la colección Selgas únicamente como el fruto de unas labores de decoración apresuradas y sin criterio fijo. Por el contrario, y a pesar de esta intención de "amueblar», se aprecian señales evidentes de un cierto espíritu coleccionista que implica una selección y un examen previo de las obras. Una de las evidencias es, por lo que respecta a los cuadros, la existencia de series temáticas, que denotan un afán consustancial al talante coleccionista y que establece una diferencia respecto a la mera acumulación de cuadros con finalidades decorativas o exhibicionistas. Otra muestra de la preocupación de los hermanos Selgas por la colección que estaban formando la constituyen las indagaciones que realizan sobre la autoría de las obras, sobre sus anteriores propietarios e incluso sobre la calidad de las mismas, asesorándose por especialistas, como, por citar un ejemplo, José Nuevo, pintor y restaurador del Museo del Prado.

Por otra parte, dentro de la voluntad de recreación de contextos históricos al hilo de los revivals finiseculares a la que se debe la colección de arte albergada en el palacio de Cudillero, es posible rastrear las preferencias de su artífice. Así, cabe destacar la magnífica colección de tapices de los siglos XVI y XVII, procedentes de las Manufacturas de Bruselas. Estos tapices renacentistas y barrocos poseen unas connotaciones historicistas que los cargan de simbolismo en un momento en que la evolución de la sociedad y de sus modos de vida los está condenando definitivamente a desaparecer.

La misma elección historicista se aprecia al examinar los estilos representados en la pinacoteca de la colección Selgas. Nos encontramos con un predominio de la pintura barroca, ya sea de motivo religioso o profano, y que comprende nombres tan señalados como Luca Giordano, Corrado Giaquinto o Vicente Carducci, por hacer referencia a maestros que trabajan dentro de nuestra península. Al margen del predominio de pintura barroca, cuenta la colección con obras maestras, como la «Ascensión de la Virgen» de El Greco, el "Ecce Homo» de Morales o el retrato del General Ricardos realizado por Francisco de Goya ${ }^{15}$, así como la recientemente descubierta obra del pintor zaragozano, «Aníbal vencedor, que por primera

15 SentenaCH, N.: «Joyas inéditas de la pintura española. Retrato del general Ricardos, por Goya», Boletín de la Sociedad Española de Excursiones, 1914, pág. 61. 


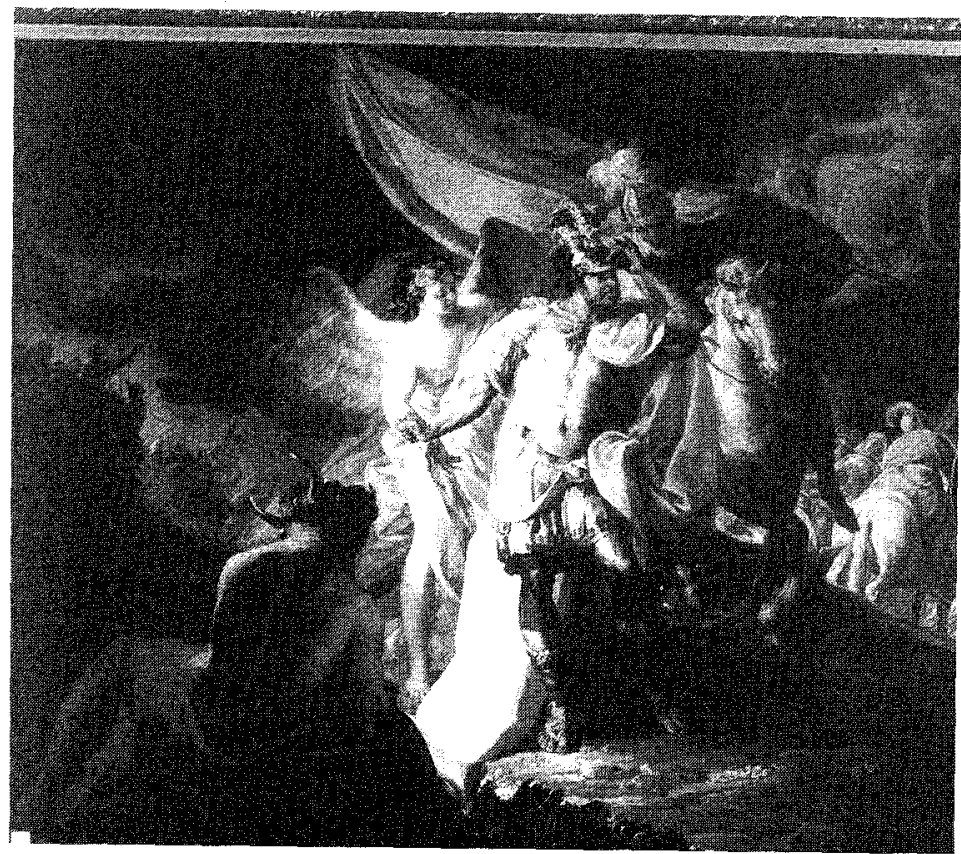

Fig. 5. Francisco de Goya: "Anibal vencedor, que por primera vez mira Italia».

vez miró Italia desde los Alpes" ${ }^{16}$, realizada para el concurso de la Academia de Parma en 1771. Todo ello es buena muestra de un gusto experto y bien definido que no se puede confundir con la mera recreación de una moda o con la imitación de las costumbres aristocráticas, máxime si tenemos en cuenta que muchos de estos maestros que gozan en la actualidad de amplio reconocimiento eran prácticamente desconocidos en el último cuarto del siglo XIX, momento en que los hermanos Selgas formaron la colección.

Como se ha señalado anteriormente, uno de los rasgos representativos de la colección de pintura reunida por los hermanos Selgas es la primacía de las series sobre las obras sueltas. Varios bocetos de la vida de San Bruno y de otros monjes cartujos que Vicente Carducci realizó entre 1629 y 1632 para la decoración del monasterio de El Paular, diversas alegorías

16 El estudio detallado de la obra y su hallazgo ha sido publicado por UREA, J.: «El Aníbal de Goya reencontrado", El Cuaderno Italiano 1770-1786. Los origenes del arte de Goya. Madrid, 1994, págs. 41-52. 
de virtudes, paisajes clasicistas de escuela romana y boloñesa o escenas del Antiguo Testamento de procedencia diversa, componen el grueso de una colección determinada por la ausencia de pintura coetánea e interesada en cambio, por las piezas del Barroco. Una de las series pictóricas más documentadas es la de la Vida de la Virgen realizada por el pintor barroco madrileño afincado en Sevilla, Francisco Antolínez y Sarabia. Fue adquirida por mediación del anticuario madrileño Rafael García a Don Leandro Velasco, procedente de la colección de un obispo de Salamanca. En su peritaje intervino José Nuevo y el escritor José de Castro y Serrano, amigos de la familia Selgas, y habituales asesores en las adquisiciones ${ }^{17}$. Series también se pueden considerar - pues su formato se ha ajustado para que así lo parezca - las colecciones de retratos conformada por piezas de procedencia heterogénea desde los de estilo barroco que siguen la tradición del retrato velazqueño, los de tinte rococó, muchos de ellos atribuibles a escuela francesa, o los de carácter romántico. Pequeñas series constituyen la pareja de grandes lienzos de Petrus Snayers sobre la Guerra de Flandes, la pareja de escenas de batallas que realizó entre 1650 y 1670 el pintor francés afincado en Milán, Jacques Courtois, o los tres temas cinegéticos del pintor alemán Philipp Peter Roos, conocido como «Rosa de Tívoli», y especializado en estas escenas en las que aúna lo bucólico con vagos referentes a la Antigüedad y que realizaba en su retiro italiano de Tívoli a mediados del siglo XVII.

Con respecto a la intención primordial de recreación del pasado resulta interesante hacer notar las características del emplazamiento de la colección. Desde mediados de siglo la familia Selgas se había establecido en Madrid, donde estaban los negocios de Ezequiel, donde Fortunato tenía su círculo erudito y donde más tarde sería nombrado Académico de Historia y Bellas Artes. Y sin embargo a la hora de pensar en un lugar propicio para situar la fastuosa residencia estival familiar que además debería albergar una valiosa colección de objetos de arte, Fortunato de Selgas decide emplazarla lejos de su lugar habitual de residencia.

La razón fundamental de esta elección es, sin duda, sentimental, pero también debió de ser determinante la posibilidad de levantar sin ningún tipo de cortapisas un espacio exclusivo y privilegiado, lleno de obras de arte y objetos preciosos que reflejasen a la perfección las aficiones y

Carta de Don Rafael García a don Ezequiel de Selgas, 14 de agosto de 1888 y Carta de Francisco Aragón a don Ezequiel de Selgas, 12 de septiembre de 1888. Archivo de la Fundación Selgas Fagalde. 
pretensiones de sus propietarios, un espacio a modo de relicario o de mundo aparte, en la misma línea que se habian concebido las cámaras de maravillas durante el Renacimiento. Idéntica filosofía coleccionista y enaltecedora de valores aristocráticos que había empujado a la elite finisecular madrileña al coleccionismo artístico. 